\title{
Prospect and Thinking on Film and Television Creation in the New Media
}

\author{
Xin Gao \\ Arts and Media College of Bohai University, Jinzhou Liaoning, 121000, China
}

Keywords: new media context; film and television creation; prospect; strategy

\begin{abstract}
The emergence of new media is based on information technology with rapid development. With the continuous development and progress of information technology and information products and the popularity of Internet technology, so-called new media emerge, different from traditional media. In the new media context, the development of film and television embraces new broad environment, and film and television creation encounter new requirements, which is the new opportunity for the development and progress of film and television creation. This paper explores the times of new media, changes of film and television creation in the new media context and prospect of film and television creation in the new media context.
\end{abstract}

\section{Introduction}

New media include digital media, network media and mobile network media, different from traditional paper media and broadcast and television media, and it can provide information for users based on network and digital technology, with network and wireless network as channels and computer, television, car TV, and mobile phone as the terminals. The new media changes ways of obtaining information, and brings more rapid information transmission and more extensive information content with reciprocal interaction. Under the broad environment, film and television creation has been impacted and shall innovate and change in content, form, structure and mode of transmission so as to adapt to the development of new media and keep stable growth of film and television media.

\section{The inevitable new media}

The new media with unique features emerge with the basic technological support from the rapid development of digital technology, communication technology and network technology, and ideological emancipation due to the integration of economy and culture in the whole world. Such new media as network video, mobile TV, mobile reading, residential block TV, car TV and etc. are based on the progress of digital and network technology, with the goal of customer requirement, which brings new opportunity and challenge for the development of traditional film and television industry. The transformation from one-sided communication of traditional film and television media to two-way communication with interaction is more beneficial for users to be engaged in the information communication. With the characteristics and advantages of itself, in the evolution and progress, new media has occupied its place in the complementary competition with traditional media. In the short term, traditional media probably will not be replaced by new media, however, new media has advantages over traditional media from the developing speed and trend.

\section{Changes of film and television creation in the new media context}

\subsection{The digitization of film and television creation}

First of all, the digitization of film and television works improves in early-stage preparations. With the rapid growth and popularity of computer technology, text processing software is more widely applied, it is more convenient to revise and store digital text and the creating writing with computer is more effective. The network realize the long-distance transmission and sharing of digital texts and provides convenience for the material collection of film and television creation. 
Besides, the development of some specific software for scriptwriting is helpful for film and television creation with higher quality and efficiency.

Secondly, characteristics of digital film and television creation are also shown in the digital production of film and television works. The production of film and television works is the key part following the script creation and post-stage processing to verify the early-stage preparations of creation and lay a foundation for post-stage processing. For instance, many characters and scenes in 3D blockbusters are accomplished with digital technology. In films like King Kong and Rise of the Planet of the Apes, digital technology is applied to integrate real person and real environment with virtual character to achieve the artistic effects.

Thirdly, digital film and television creation is also demonstrated in the post-stage processing. For instance, in reality show, digital method is used for the film editing to increase the appeal of show with computer animation technology to enrich frames. In addition, animation technology is applied in television creation to produce more natural plot and vivid psychological description.

\subsection{More extensive theme selection and story form and structure with interest and topicality based on characteristics of new media}

In new media context, there are more authors of novel writing on Internet, and a large number of excellent works with many readers, which has a beneficial influence on the recreation of film and television works. For example, several adaptation films are created based on the novel series of The Ghouls with the expectation of fans of the original work in the beginning of production, which is helpful for the film marketing promotion. Take Empresses in the Palace as an example. It attracts a large number of fans and becomes hot drama in the new media platform, and popular drama as Princess Pearl on television especially in summer and winter holidays. In addition, low-middle budget films in new media context have attracted the audience in story line and conception, which is more consistent with the real life of the public, and story line resonates with the audience with many laugh and tears. The interest and topicality of film creation in new media context is more emphasized. The feelings of the audience is different, therefore, in order to satisfy the demand of more people, the introduction of famous stars and relevant topics in film creation brings more interest and topicality of films.

\subsection{Diversified story forms of film creation in new media context with interactive storytelling to indicate aesthetic characteristics}

In the new media context, the story form of film and television works is more diversified, which is determined by interactive, changeable and rich characteristics of new media. The interaction breaks the creation order of traditional media, thus, diversified stories become the foundation of film and television creation. More varied stories such as myth play, suspenseful detective play and medical show have been presented to the audience. Besides, the interaction of new media also has an impact on the expression of film and television creation. The interactive storytelling is applied in the story line to demonstrate aesthetic characteristics of film and television works. The interactive storytelling takes writer, story and audience as a whole to guide the audience to improve and create story and accept the aesthetic characteristics of writer, mainly including AB selection, multi-view, and time-series combination, which shows the openness in new media context, demonstrates the enthused participation of the audience with highly free selection of film and television works, changes the limits of soul communication between works and the audience, and brings interaction and experience for film and television works in new media context.

\section{Prospect of film and television creation in new media context}

\subsection{The artistry and technology in film and television creation}

In new media context, digital technology is widely used in film and television creation for better technological conditions, which makes magnificent scenes, super power method of riding on clouds or controlling the forces of the nature, the simulation reduction of disastrous weather or disaster 
scene possible. However, film and television creation is still required to keep artistry. Digital technology is the external methods to create shock and appealing, but what touches the audience most is the internal "spirit", which is the base of the film and television creation to develop healthily, if lost, the magnificent frames are all empty. For instance, Chinese and foreign films such as Monkey King: Hero is Back, Inception, Crazy Stone, and Rise of the Planet of the Apes have good story as the spirit, and appealing due to digital technology, wining box office and public praise.

\subsection{The indigenous and international film and television creation}

The relationship between each nation is close due to the economic and cultural globalization. Therefore, the film and television creation should be indigenous and international both. The more national, the more of the world. Film and television creation shall keep characteristics of its own country and nation before going out the world, in this way, the culture, philosophical thinking, and national dignity and etc. can be well understood by other nations. When the film and television creation in our country is indigenous and international at the same time, film and television industry and culture can develop for a longer time. At present, Chinese element is added to films of foreign enterprises in many countries, which is, however, actually marketing methods to increase box office. Therefore, Chinese indigenous cultural film and television works can only be produced by Chinese film and television companies because they can really understand Chinese culture and can make full use of Chinese element. Currently it is most important to improve the creation capability and production of domestic film and television companies with indigenous and international film and television creation as the goal to make Chinese film and television works popular at home and abroad. The same is true for the creation of television programs. It is necessary to absorb the essence of foreign entertainment programs, but also combine the characteristics of local culture and reflect the excellent quality of the Chinese nation. The entertainment programs produced in China can also become excellent TV programs for foreign television stations to compete for the right to purchase, and accomplish the output of Chinese film and television industry.

\subsection{The cultural and commercial film and television creation}

The creation of film and television shall be cultural and commercial at the same time. Film and television works belong to artistic works, a kind of cultural product with cultural feature itself. And it can be sold as a commodity with commercial feature. In new media context, the continuous healthy development of film and television arts shall follow market discipline and commercial value of itself, and improve its connotation and cultural significance. The film and television industry shall be cultural and commercial at the same time to create works with high quality and conduct commercial promotion rationally.

\subsection{The film and television creators should continuously improve their comprehensive quality and competence.}

In new media context, film and television creators need to continuously improve their comprehensive quality and competence. Scriptwriters should improve their literature accomplishment and writing proficiency, based on life experience and feelings, and create good scripts with imagination and innovation. Directors shall grasp production rules of traditional film and television art, at the same time, understand deeply digital technology and create film and television works based on the advanced technological methods. The post-stage production staff need to strengthen their speciality and improve the post-stage processing of film and television works.

\section{Conclusion}

In conclusion, the prosperous development of new media brings new life and vitality for film and television creation. In new media context, the theme selection and story form are more extensive in film and television creation, which shows the characteristics of interactive storytelling. In the future development, film and television creation shall be aesthetic and technological, indigenous and 
international, cultural and commercial, and it can develop continuously and benignly.

\section{References}

[1] Zhao Ziyan. The Studies on The Digitalization of Movie \& TV Art in New Media Time [D]. Harbin Normal University, 2012 (06).

[2] Luo Yuan. The Interaction between Book Industry and Film-television Industry in New Media Time [J]. A Vast View on Publishing, 2015, (15): 82-83.

[3] Dai Jiayan. Film and TV Remodeling of Traditional Literary Classics in New Media Age [J]. Journal of Tonghua Normal University, 2014, (6): 128-131. 